\title{
Roof Slope Calculation by the Shape of Building through Utilizing
} UAV

\author{
Min-Seok Kim ${ }^{1}$, Seung-Wook Lee ${ }^{2}$, Yoon-Ki Hong ${ }^{3}$, Seung-Chan Baek ${ }^{4}$, Won- \\ Hwa Hong ${ }^{5}$ \\ ${ }^{1}$ School of Architectural, Civil, Environmental and Energy Eng., \\ Kyungpook National University of Daegu, Korea. \\ ${ }^{2}$ Department of Spatial Information, \\ Kyungpook National University of Daegu, Korea. \\ ${ }^{3}$ Department of Spatial Information, \\ Kyungpook National University of Daegu, Korea. \\ ${ }^{4}$ School of Architectural Civil Environmental and Energy Eng., \\ Kyungpook National University of Daegu, Korea. \\ $5_{*}$ School of Architectural Civil Environmental and Energy Eng. \\ Kyungpook National University of Daegu, Korea. Corresponding author. \\ ${ }^{1}$ kms910601@gmail.com,20309sw@gmail.com.bless1119@hanmail.net, \\ ${ }^{4}$ seungchan1318@gmail.com, 5*hongwh@kmu.ac.kr
}

\begin{abstract}
In order to utilize the roof space of the building correctly calculated roof area is required. However, existing calculation methods of rof area have problems such as the hassle of on-site measurements and is of the calculation formula which has an incorrect element. Therefore, this study conducted a basic research to establish a faster and more accurate calculation method compared to the traditional calculation method by utilizing UAV. Aerial photographs of the target site were obtained by using UAV and Orthophoto and DEM were generated based on this. Among 54 investigation target buildings, 41 buildings were classifled by the roof shape of buildings, except for 13 buildings with a flat roof. Also, the roof stope of 41 builaings was measured by applying the Slope of ArcMap to generated DEM.
\end{abstract}

Keywords. UAV, 3D Modeling, Roof Slope, DEM, ArcMap

\section{Introduction}

\subsection{Background and Purpose of the Research}

Since the development of CGIS in the 1960s, application of GIS field has been gradualy expanded such as Land Information System(LIS), Urban Information system(UIS), Surveying Information System(SIS), etc. Although currently researches using GIS have been actively conducted and the need for roof utilization increases, it's a situation that the study on the root area which becomes basic data for roof utilization is still insufficient. In existing roof area measurement method, there's a hassle that target buildings need to be measured individually through onsite measurements. Also, in the way of using a calculation formula, there's an issue in accuracy as the roof slope is roughly estimated. Therefore, this is a basic research to establish a faster and more accurate calculation method compared to the traditional calculation method. The roof slope which is an output element of the roof area calculation is measured by generating Orthophoto and DEM based on aerial photographs acquired by utilizing UAV. 


\subsection{Research Method and Scope}

In order to perform this study, aerial photographs of buildings in the target site were taken by using UAV and Orthophoto and DEM were generated based on this. Based on obtained maps and Orthophoto of the target site, roof types Plan type of buildings were classified and survey on buildings were conducted. As a follow-up of this, slopes were formed on DEM of the target site by using ArcMap so that the slope for each shape of buildings was measured. A flow diagram of study is shown in Figure 1.

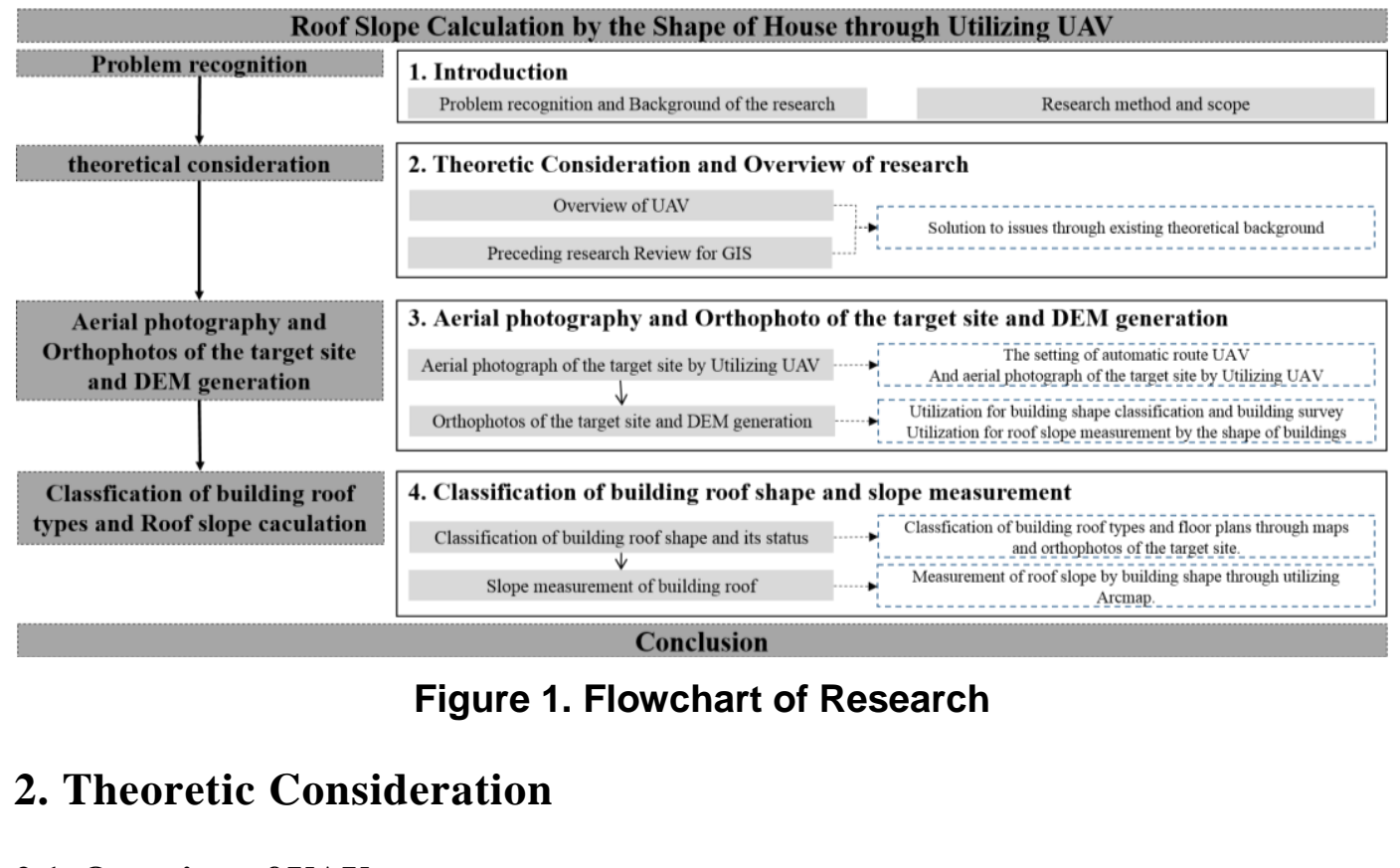

\subsection{Overview of UAV}

UAV refers to an aircraft which flies automatically without a pilot in the aircraft according to the program made in advance or a pilot controls it remotely from the ground and a system which aircraft need to fly. [1] UAV has been utilized in various fields, such as construction, broadcasting, environment, military, etc. and research on photogrammetry using a UAV in the spatial information field also has been actively in progres 8 Aro [3] application researches using UAV which has a low operation cost, as aerial measurement equipment instead of [2] the traditional expensive aerial mapping system and its accuracy assessment have been actively conducted [4].

\subsection{Overview of GIS}

Regarding GIS, CGIS was developed for the first time for resource management in Canada in the 1960s. GIS is an information system to collect, observe and measure geographic information, convert to computer data and utilize effectively it. [5] While GIS is being developed, the study of application plans in numerical geologic map, topography, satellite data, etc. is underway in a wide range of fields. [6] The contour accuracy of mountains and hills are analyzed and the terrain slope measurement [8] through DEM [7] and measurement study of the amount of soil erosion by using the flow and coast slope [9] have been in progress. However, it's a situation that the study on building roof which is considered to be used mostly is insufficient. 


\section{Aerial Photography and Orthophoto of the Target Site and DEM Generation}

\subsection{Overview of the Target Site and Aerial Photography}

The area of 137 to 141 street, Namsan-dong, Jung-gu, Daegu which is the class 3 of general residential area where the overall renovation is needed due to its old buildings in the area and it's difficult to measure the actual roof area was selected as a target site in this study. The area of the target site is $11,500 \mathrm{~m}^{2}$ and 54 buildings based on the building registers were investigated in the area.

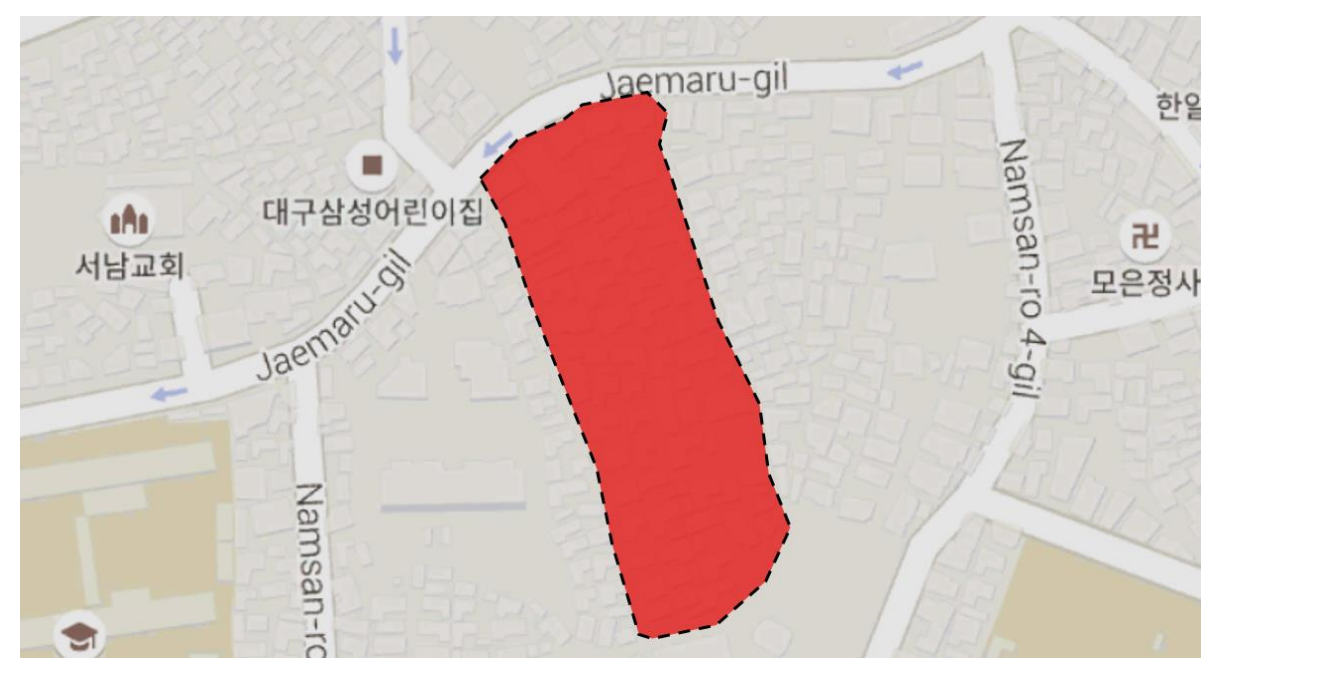

Figure 2. Target Area of Study (Source: Google Map)

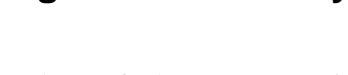

For the aerial photography of the target site, automatic flight path of UAV was set up by utilizing the Mission Planner. The aerial photography range is $16,540 \mathrm{~m}^{2}$ and a total of 110 aerial photographs were obtained by setting $140 \mathrm{~m}$ for UAV flight altitude. The flight plan and aertal photographs were shown in Figure 3.

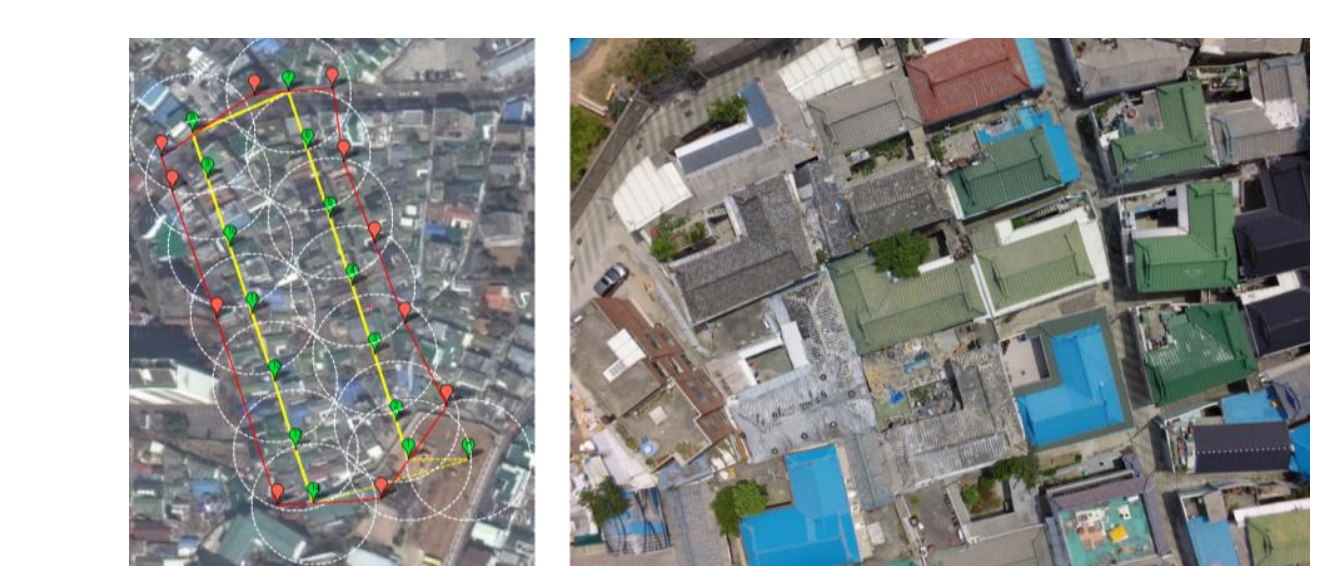

Figure 3. Flight Plan and Aerial Photograph

\subsection{Orthophoto and DEM Generation of the Target Site}

PhotoScan S/W made by Agisoft was used to generate Orthophoto and DEM based on obtained aerial photographs. Regarding the order of operation, it was carried out in the order of Align Photos - Build Dense Cloud - Build Mesh - Build Texture. Positioning the camera is made by sorting pictures taken in Align Photos 
stage. Build Dense Cloud operation calculates the depth information to generate into a single Dense Cloud based on the position of the camera. 3D modeling is created by mesh after Build Dense Cloud operation and after that, the original image was mapped on the generated mesh through Build Texture operation. In Figure 4 and Figure 5 images after each operation, Orthophoto and DEM of the target site are shown.

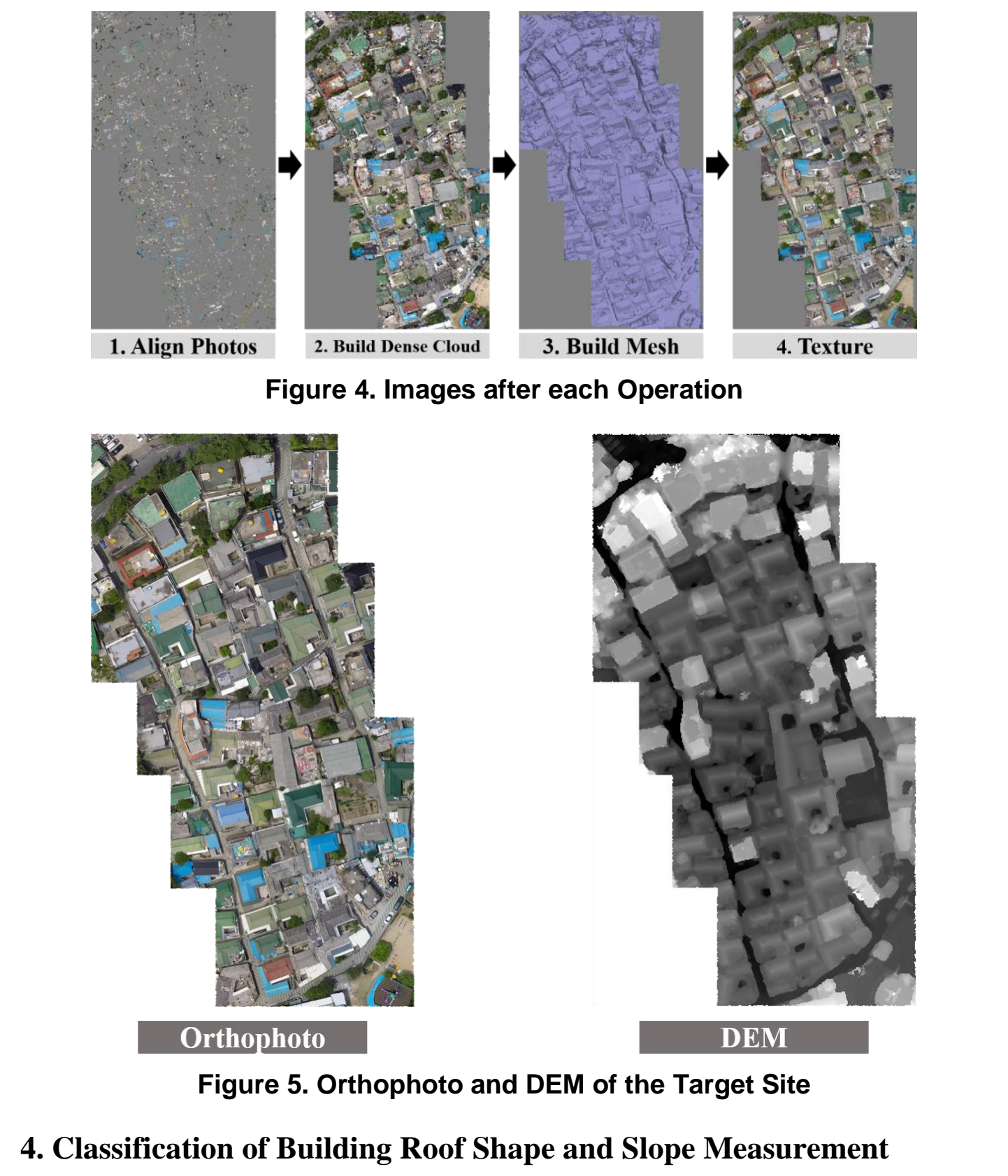

\subsection{Classification of Building Roof Shape and its Status}

Based on the generated Orthophoto and maps of the target site, building roofs in the area were classified by shape. The roof type is classified into single type and hybrid type depending on its shape and they are further classified in detail by design. The single roof type of 54 buildings in the target site includes Dutch Gable, Flat, Gable and Hip and the hybrid includes Dutch Gable + Flat, Gable, Hip, Gable + Gable and Hip + Hip. In addition, they are classified into I, U, and L types 
depending on roof's Plan Type. The status of building roof shape in the target site is shown in Table 1.

\section{Table 1. The Status of Building Roof Shape in the Target Site}

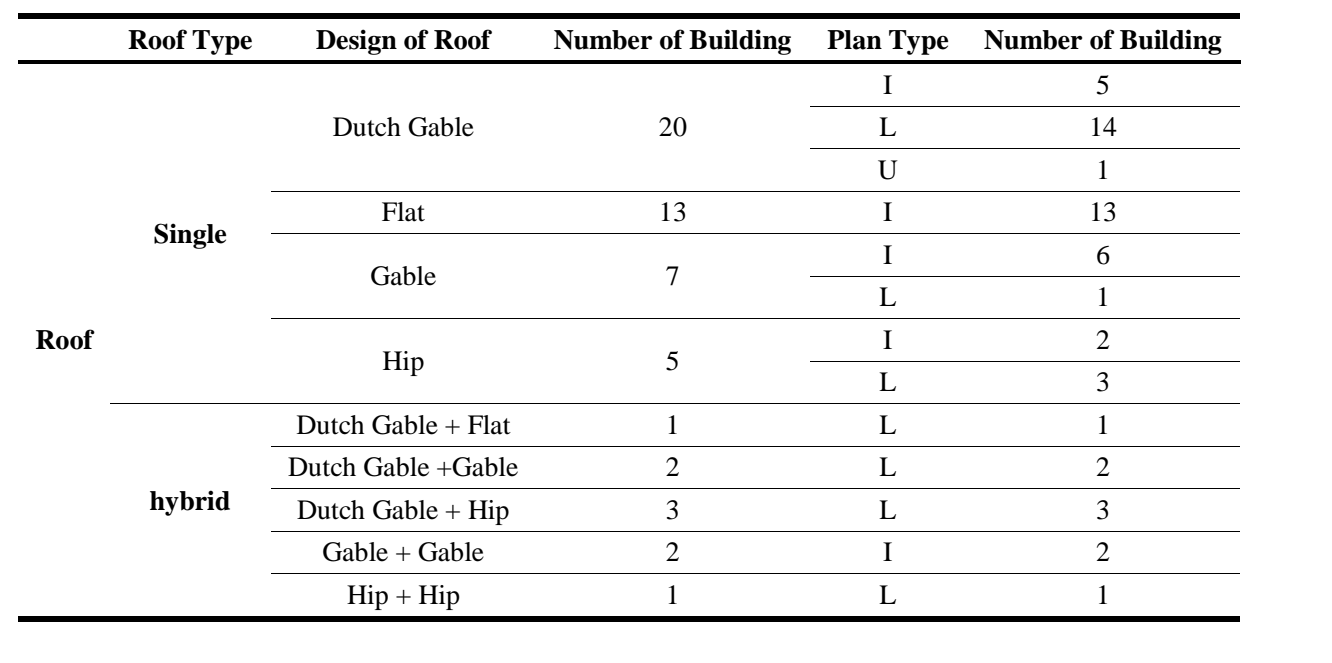

\subsection{Slope Measurement of Building Roof}

Slope was measured based on Orthophoto and DEM. After a polygon of roof shape is formed based on the Orthophoto, roof slope was measured by utilizing the Slope(Spatial Analyst) in ArcMap. The roof slope was measured at six points of the respective roof surface and through the arithmetic ayerage it was calculated for the mean value of the slope for roof surface. Theprocess for the measurement of roof slope was shown in Figure 6.

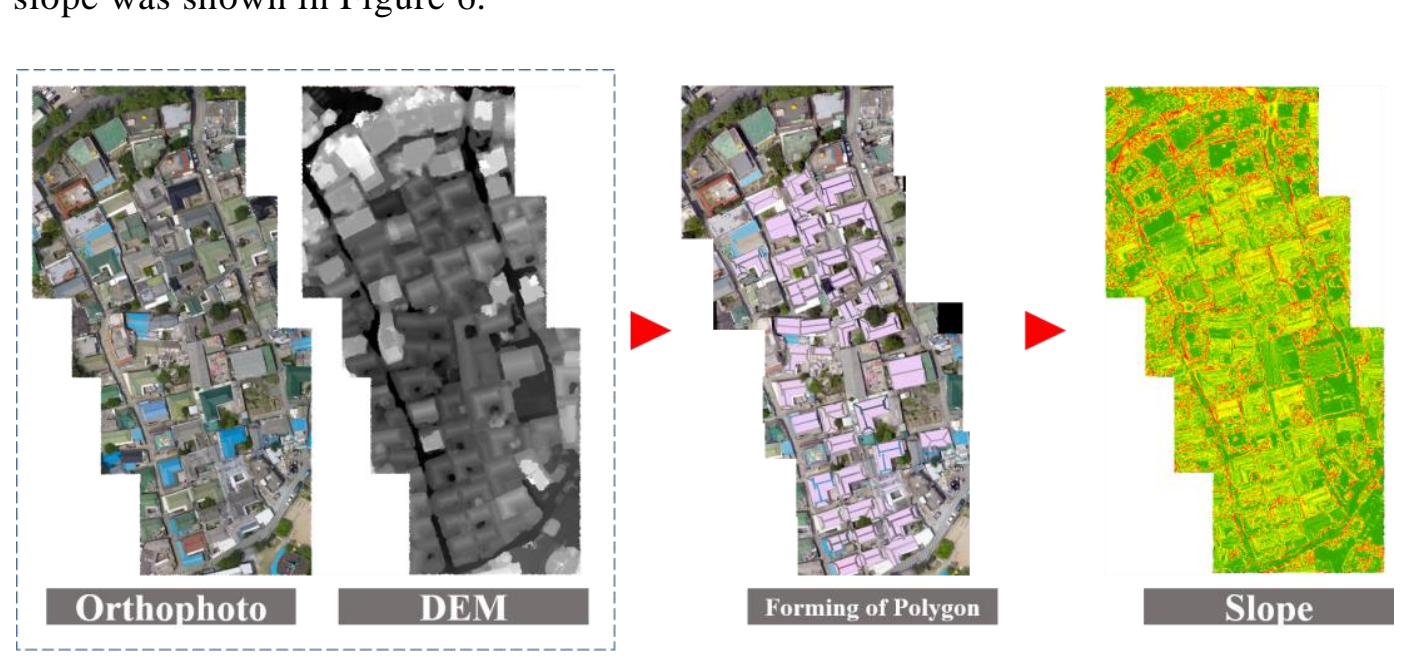

Figure 6. Workflow of Roof Slope Measurement

Roof slopes of buildings in the target site were measured based on the pictures obtained throughUAV. Measured slope values of each shape are shown in following Table 2, 3, 4, 5 and 6. 
Table 2. Roof Slope of Single Type U (Unit: ${ }^{\circ}$ )

\begin{tabular}{cccccccccccc}
\hline No. & Type & Design of Roof & Plan Type & A & B & C & D & E & F & G & H \\
\hline 1 & Single & Dutch Gable & U & 37.62 & 29.92 & 25.92 & 26.53 & 31.20 & 31.74 & 30.77 & 38.34 \\
\hline
\end{tabular}

Table 3. Roof Slope of Single Type I (Unit: ${ }^{\circ}$ )

\begin{tabular}{cccccccc}
\hline No. & Type & Design of Roof & Plan Type & A & B & C & D \\
\hline 1 & Single & Dutch Gable & I & 31.77 & 37.91 & 25.76 & 28.69 \\
2 & Single & Dutch Gable & I & 27.00 & 28.48 & 35.64 & 31.06 \\
3 & Single & Dutch Gable & I & 26.07 & 26.32 & 34.91 & 29.58 \\
4 & Single & Dutch Gable & I & 25.09 & 27.71 & 36.97 & 31.91 \\
5 & Single & Dutch Gable & I & 26.77 & 23.80 & 31.69 & 32.67 \\
6 & Single & Gable & I & 31.42 & 27.26 \\
7 & Single & Gable & I & 21.87 & 23.29 \\
8 & Single & Gable & I & 24.73 & 22.65 & \\
9 & Single & Gable & I & 15.62 & 15.12 & \\
10 & Single & Gable & I & 35.04 & 35.13 & \\
11 & Single & Gable & I & 13.99 & 17.15 & \\
11 & Single & Hip & I & 22.68 & 21.01 & 25.11 \\
12 & Single & Hip & I & 29.69 & 28.00 & 27.51 \\
\hline
\end{tabular}

Table 4. Roof Slope of Single Type L (Unit: ${ }^{\circ}$ )

\begin{tabular}{|c|c|c|c|c|c|c|c|c|c|}
\hline No. & Type & Design of Roof & Plan Type & $\mathbf{A}$ & B & $\mathrm{C}$ & $\vec{D}$ & $\mathbf{E}$ & $\mathbf{F}$ \\
\hline 1 & Single & Dutch Gable & $\mathrm{L}$ & 29.03 & 36.82 & $31.7 \overline{7}$ & 29.16 & 34.20 & 32.32 \\
\hline 2 & Single & Dutch Gable & $\mathrm{L}$ & 35.93 & 31.92 & 32.01 & 30.41 & 30.84 & 32.79 \\
\hline 3 & Single & Dutch Gable & $\mathrm{L}$ & 30.27 & 41.05 & 35.36 & 31.68 & 34.68 & 36.78 \\
\hline 4 & Single & Dutch Gable & $\mathrm{L}$ & 27.54 & 31.39 & 28.21 & 27.36 & 31.11 & 31.14 \\
\hline 5 & Single & Dutch Gable & & 35.25 & 30.57 & 32.08 & 38.20 & 33.45 & 34.69 \\
\hline 6 & Single & Dutch Gable & & 28.53 & 3192 & 30.1 & 30.96 & 32.3 & 14.63 \\
\hline 7 & Single & Dutch Gable & & 29.37 & 21.13 & 22.21 & 25.79 & 28.93 & 28.00 \\
\hline 8 & Single & Dutch Gable & & 33.45 & 24.12 & 27.68 & 26.81 & 22.99 & 27.79 \\
\hline 9 & Single & Dutch Gable & & 29.17 & 31.88 & 33.16 & 34.79 & 36.36 & 31.64 \\
\hline 10 & Single & Dutch Gable & & 36.42 & 31.61 & 27.24 & 29.74 & 32.05 & 36.93 \\
\hline 11 & Single & Dutch Gable & $\mathrm{L}$ & 2873 & 23.09 & 30.07 & 28.16 & 26.31 & 27.10 \\
\hline 12 & Single & Dutch Gable & & 31.79 & 22.23 & 26.87 & 24.07 & 24.49 & 28.33 \\
\hline 13 & Single & Dutch $\mathrm{Gab}$ & & 30.64 & 28.18 & 27.02 & 28.24 & 29.92 & 29.62 \\
\hline 14 & Single & & 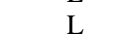 & 31.74 & 34.69 & 30.35 & 30.50 & 33.64 & 33.46 \\
\hline 15 & Single & & & 15.74 & 13.43 & 12.35 & 12.11 & & 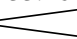 \\
\hline 16 & Single & & & 31.75 & 38.90 & 32.06 & 28.98 & 32.08 & 35.48 \\
\hline 17 & Single & & L & 34.03 & 28.42 & 17.48 & 18.83 & 25.91 & 24.24 \\
\hline 18 & Single & Hip & $\mathrm{L}$ & 28.64 & 29.15 & 24.56 & 27.25 & 27.90 & 40.09 \\
\hline & No. & Desig & Roof & Plan Type & A & B & $\mathrm{C}$ & D & \\
\hline & 1 & Gabl & able & I & 23.55 & 23.82 & 24.58 & 22.61 & \\
\hline & 2 & Gabl & able & I & 36.01 & 26.04 & 26.93 & 25.22 & \\
\hline
\end{tabular}

Table 6. Roof Slope of Hybrid Type L (Unit: ${ }^{\circ}$ )

\begin{tabular}{|c|c|c|c|c|c|c|c|c|c|c|c|}
\hline No. & Type & Design of Roof & Plan Type & $\mathbf{A}$ & B & C & D & $\mathbf{E}$ & $\mathbf{F}$ & $\mathbf{G}$ & H \\
\hline & hybrid & Dutch Gable + Flat & $\mathrm{L}$ & 24.65 & 27.44 & 29.62 & 20.85 & & & & \\
\hline & hybrid & Dutch Gable + Gable & $\mathrm{L}$ & 25.30 & 27.86 & 19.58 & 19.46 & 30.53 & 32.36 & & \\
\hline 3 & hybrid & Dutch Gable + Gable & $\mathrm{L}$ & 25.16 & 21.91 & 25.59 & 25.39 & 27.02 & & & \\
\hline 4 & hybrid & Dutch Gable + HIP & $\mathrm{L}$ & 39.86 & 30.11 & 27.07 & 29.44 & 28.46 & 34.86 & & \\
\hline 5 & hybrid & Dutch Gable + Hip & $\mathrm{L}$ & 27.25 & 33.31 & 28.95 & 24.71 & 31.36 & 31.53 & & \\
\hline 6 & hybrid & Dutch Gable + Hip & $\mathrm{L}$ & 33.26 & 33.02 & 34.39 & 29.65 & 27.45 & 29.60 & & \\
\hline 7 & hybrid & Hip + Hip & $\mathrm{L}$ & 18.96 & 22.44 & 21.28 & 19.90 & 20.71 & 20.66 & 25.54 & 27.21 \\
\hline
\end{tabular}




\section{Conclusion}

In this study, Orthophoto and DEM are generated based on aerial photographs obtained by utilizing UAV. Buildings in the target site were classified by Shape of Building by utilizing Orthophoto and map of the target site and then were measured. The results of this study are as follows.

First, aerial photographs of the target site were obtained by utilizing UAV and Orthophoto which shows the elements of the building roof was generated based on this.

Second, roof types were clarified based on the Orthophoto of the target site. Regarding the status of buildings in the target site, it was classified into 5 buildings of Dutch Gable I, 14 buildings of Dutch Gable L, 1 buildings of Dutch Gable U, 13 buildings of Flat I, 6 buildings of Gable I 6, 1 buildings of Gable L, 2 buildings of Hip I, 3 buildings of Hip L, 1 buildings of Dutch Gable + Flat L, 2 buildings of Dutch Gable + Gable L, 3 buildings of Dutch Gable + Hip L, 2 buildings of Gable 4 Gable I, and one buildings of Hip + Hip.

Third, the roof slope of buildings in the target site was measured by utilizing DEM based on classified roof elements and from this, the roof slope of buildings in the target site was measured by using UAV. The roof area carcalation method conducted in this study is believed to be used as basic data in the future for the roof area calculation formula which is needed for the exact roof area calculation to take advantage of roof such as BIPV and RWH systeminstallations.

\section{Acknowledgments}

This work was supported by the National Research foundation of Korea(NRF) grant funded by the Korea government(MSIP) (NRF-2016R1A2A1A05005459).

\section{References}

[1] Min-Woo Choi, "The St ategy of Development for Korea Type - Unmanned Air Vehicle". Master's Thesis, Kangon University, Chuncheon, Korea, (2010)

[2] Jun-Hee Jo, "Accuracy and Economic Feasibility Study of Orthoimage Map Production using UAV". Master's Thesis, The University of Seoul, Seoul, Korea, (2014)

[3] Sung-Heuk Jung, Hyeong-Min Lim Jae-Kee Lee, "Acquisition of 3D Spatial Information using UAV Photogrammetric Method" The Journal of the Korean Society Surveying, Geodesy, Photogrammetry and Cartography, Vol. 28, No.1, (2010), pp. 161-167.

[4] In-Su Lee, Jae-One Lee Su Jeong Kim, Soon-Heon Hon

[5] g, "Orhtophoto Accuracy Assessment of Ultra-light Fixed Wing UAV Photogrammetry Techniques", Journal of the Koreansociety of Civil Engineers, Vol. 33, No. 6, (2013), pp. 2593-2600.

[6] Korea National Spatial Data Infrastructure Portal, "The history of GIS", http://www.nsdi,go.kr/?menuno=2726

[7] Su-Young Kang, Kwang Hee Kim, "Effects of DEM Resolutions in Site Classification", Journal of the Korean society for geo-spatial information system, Vol. 19, No. 1, (2011), pp. 21-28.

[8] Jin-Min Shin, Kyoo-Seok Lee, "A Study on the Accuracy of Calculating Slopes for Mountainous Candform in Korea Using GIS Software", The Journal of GIS Association of Korea, Vol. 7, No. 1, (1999), pp. 35-43.

[91 Eun-su Seo, Se-Hyu Choi, "Slope Analysis and Classification of Hiking Trails Using GIS", Journal of Korea Spatial Information Society, Vol. 20, No. 1, (2012), pp. 1-7.

[10] Geun-Sang Lee, Yun-Woong Choi, Gi-Sung Cho, "Suggestion of Slope Evaluation by DEM-based Aggregation Method", Journal of The Korean Society of Civil Engineers D, Vol. 26, No. 6D, (2006), pp. 1019-1023.

[11] Sook-Kyung Hong, "A Study on the Varieties of Exterior Shapes Expressed on Houses of Korea". Master's Thesis, Chung-Ang University, Seoul, Korea, (2001).

[12] Sung-chin Oh, "A Study on the Types of Apartment Roof Design and and Residents' Preference in Metropolitan Seoul Area”. Master's Thesis, Ajou University, Suwon, Korea, (2004).

[13] Min-Seok Kim, Seung-Wook Lee, Yoon- Ki Hong, Seung-Chan Baek, Won-Hwa Hong, "A Study on the Roof Slope Calculation of the Detached House by Utilizing UAV", Advanced Science and Technology Letters, Vol. 124, (2016), pp. 109-114. 
[14] Jae-One Lee, Dong-Rak Lee, Bu-Yeol Yun, Hye-Won Choi, "The Newest Application of UAV for Implementation of Geo-Spatial Information", Korea Society of Surveying, Geodesy, Photogrammetry, and Cartography, (2013), pp. 157-159.

[15] Seung-Wook Lee, Won-Hwa Hong, Seung-Yeob Lee, "A Study on Slate Roof Research of Decrepit Residential Area by Using UAV" Journal of the architectural institute of Korea planning \& design, Vol. 32, No.3, (2016), pp. 59-66.

\section{Authors}

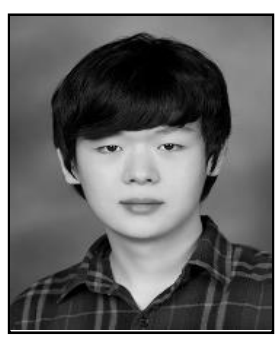

\section{Min-Seok Kim}

Graduate Student

School of Architectural, Civil, Environmental and Energy

Engineering

Kyungpook National University, 80 Daehakro, Bukgu, Daegu, Rep. of Korea.

kms910601@gmail.com

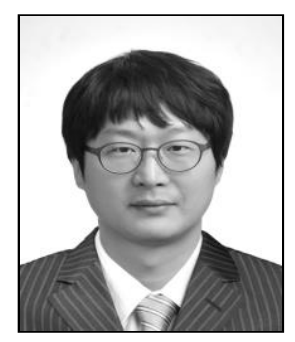

\section{Seung-Wook Lee}

Ph.D.

Department of Spatial Information

Kyungpook National University 80 Daehakro, Búkgu, Daegu, Rep. of Korea.

0309sw@gmail.com

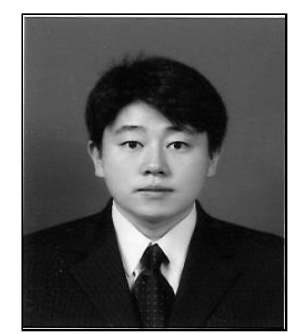

\section{Yoon-Ki Hoong}

Ph.D. Student,

Department of Spatial Information

Kyungpook National University, 80 Daehakro, Bukgu, Daegu, Rep. of Borea.

bless119@hanmail.net

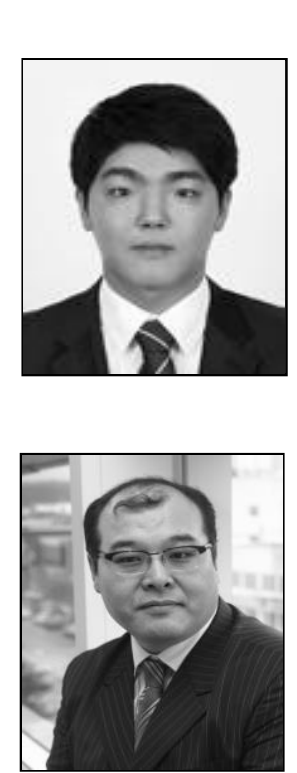

\section{Seung Chan Baek}

PbD. Student

School of Architectural, Civil, Environmental and Energy

Engineering

Kyungpook National University, 80 Daehakro, Bukgu, Daegu, Rep. of Korea.

seungchan1318@gmail.com

\section{Won-Hwa Hong}

Professor, Corresponding author

School of Architectural, Civil, Environmental and Energy

Engineering

Kyungpook National University, 80 Daehakro, Bukgu, Daegu, Rep. of Korea.

hongwh@knu.ac.kr 